\title{
CARACTERIZAÇÃO ISOZIMÁTICA E ATIVIDADE DE PEROXIDASE EM FOLHAS DE PLÁNTAS HIPERÍDRICA, INTERMEDIÁRIA E NORMAL DE Bidens pilosa L. MANTIDAS IN VITRO
}

\author{
Isoezymatic characterization and peroxidase activity in leaves of hyperhydric, intermediary and \\ normal plants of Bidens pilosa $\mathrm{L}$. grown in vitro
}

\author{
José Emílio Zanzirolani de Oliveira', Cláudio Lúcio Fernandes Amaral², Vicente Wagner Dias Casali
}

\begin{abstract}
RESUMO
Foram caracterizadas as plantas: hiperídrica, intermediária e normal de um clone de Bidens pilosa mantido em cultivo in vitro por meio de isozimas e da atividade de peroxidase. Empregando-se a eletroforese em géis de amido a 12\%, testou-se seis isozimas, sendo detectado polimorfismo em peroxidase e fosfatase ácida, permitindo caracterizar cada tipo de planta. Não houve polimorfismo em fosfogluco isomerase, fosfoglucomutase, glutamato oxaloacetato transaminase e malato desidrogenase. A atividade da peroxidase foi maior nas plantas hiperídricas e intermediárias. Conclui-se que a variabilidade enzimática tem potencial como marcador de hiperidricidade em plantas mantidas in vitro.
\end{abstract}

Termos para indexação: Isozima, hiperidricidade, vitrificação.

\section{ABSTRACT}

Activity of peroxidase (EC 1.11.1.7) and isozymes analysis of a Bidens pilosa clone maintained in vitro culture were characterized in hyperhydric, intermediary and normal plants. Electrophorese in starch gels (12\%) of six isozymes systems was tested, polymorphisms in peroxidase and acid phosphatase (EC 3.1.3.2) were detected. There was absence of polymorphism in phosphoglucoisomerase (EC 5.3.1.9), phosphoglucomutase (EC 5.4.2.2), glutamate oxaloacetate transaminase (EC 2.6.1.1) and malate dehydrogenase (EC 1.1.1.37). Comparing the activity of peroxidase enzyme, it was higher in hyperhydric and intermediary plants in relation to normal ones. Enzymatic variability is a potential tool as hyperhydricity marker in plants grown in vitro.

Index terms: Isoenzyme, hyperhydricity, vitrification.

(Recebido em 26 de abril de 2006 e aprovado em 30 de outubro de 2006)

\section{INTRODUÇÃO}

Bidens pilosa L., popularmente conhecida como picão-preto, ocorre espontaneamente em regiões tropicais e subtropicais desde o nível do mar até cerca de $3000 \mathrm{~m}$ de altitude, acompanhando os seres humanos e seus cultivos. Tem sido utilizada como alimento e remédio, nos problemas relacionados ao fígado e nos casos de anemia ferropriva (OLIVEIRA \& CASALI, 1999; VALDES \& REGO, 2001). Em espécies de ampla dispersão, como B. pilosa, a variabilidade genética é fundamental na adaptação e sobrevivência aos ambientes diversos e adversos (OLIVEIRA \& CASALI, 1999), in vivo ou in vitro.

A variabilidade in vitro pode ser observada com graus de crescimento e desenvolvimento e/ou, quando ocorre, hiperidricidade. A hiperidricidade, desordem fisiológica, bioquímica e morfológica, pode ser encontrada em todos os tecidos em cultivo in vitro e detectada por meio de análises isozimática e da atividade enzimática (KEVERS et al., 2004; SAHER et al., 2004).

Em cultura de tecidos, a temperatura ótima na sala de crescimento, na maioria das espécies vegetais, está entre 20 e $27^{\circ} \mathrm{C}$ (GRATTAPAGLIA \& MACHADO, 1998). Em temperatura mais elevada, o meio fica menos consistente, o explante imerge no meio e absorve nutrientes em excesso, gerando hiperidricidade (CHEN \& ZIV, 2001; CUZZUOL et al., 1995).

A hiperidricidade é reversível, tem grau variado e pode acometer apenas parte dos explantes em cultivo. $\mathrm{Na}$ planta hiperídrica, as folhas e os caules são: longos, finos, enrugados, quebradiços, pouco lignificados, muito hidratados, deficientes em clorofila e fenóis solúveis (CHEN \& ZIV, 2001). Nessas plantas, há diminuição na quantidade dos propágulos úteis, pois as raízes podem estar ausentes, reduzidas e/ou com modificação no

\footnotetext{
${ }^{1}$ Biólogo, D.S., Professor da Escola de Ciências Naturais e Exatas - Universidade do Estado de Minas Gerais/UFMG - Campus Ubá - Ubá, MG jezoliveira@hotmail.com

2Biólogo, D.S., Professor do Departamento de Ciências Biológicas na Universidade Estadual do Sudoeste da Bahia/UESB - Campus Universitário 45.200-000 - Jequié, BA - geneticamaralclfuesb@bol.com.br

${ }^{3}$ Engenheiro Agrônomo, Ph.D, Professor Titular do Departamento de Fitotecnia na Universidade Federal de Viçosa/UFV - Campus da UFV - $36570-000$ Viçosa, MG - vwcasali@ufv.br
} 
geotropismo (CUZZUOL et al., 1995). Esses danos podem ser alteração da atividade de inúmeras enzimas. O estresse oxidativo, envolvendo os radicais livres (superóxidos e hidroxilas) e o peróxido de hidrogênio $\left(\mathrm{H}_{2} \mathrm{O}_{2}\right)$, induz a hiperidricidade em cultivo in vitro (CHEN \& ZIV, 2001; SAHER et al., 2004). A sobrevivência vegetal depende da presença de moléculas reduzidas e enzimas antioxidantes, como peroxidase (CHEN \& SCHOPFER, 1999; SAHER et al., 2004).

Neste estudo, plantas de um clone de Bidens pilosa com características hiperídricas, intermediárias e normais, mantidas in vitro, foram avaliadas por meio de sistemas isozimáticos e de atividade da peroxidase nas folhas, visando detectar resposta bioquímica diferencial.

\section{MATERIAL E MÉTODOS}

As plantas foram coletadas em Leopoldina-MG (altitude 210 m, agosto de 1999) e levadas à Universidade Federal de Viçosa (UFV). No Herbário do Departamento de Biologia Vegetal (VIC) foram herborizadas, depositadas e registradas com o número 25.311 e identificadas como Bidens pilosa L. (Asteraceae).

O cultivo in vitro foi feito, no ano de 2000, no Laboratório de Testes de Progênie do Departamento de Fitotecnia (DFT) da UFV. O meio utilizado foi o MS (pH 5,7) solidificado com 7,0 $\mathrm{g} \mathrm{L}^{-1}$ de ágar, sem reguladores de crescimento. Cada tubo de ensaio $(24 \times 150 \mathrm{~mm})$ recebia $15 \mathrm{~mL}$ desse meio e eram autoclavados $\left(121^{\circ} \mathrm{C}\right.$ por 15 minutos). Iniciou-se o cultivo com sementes, cuja assepsia prévia foi feita em câmara de fluxo de ar laminar estéril utilizando-se benomyl em solução aquosa $\left(2 \mathrm{~g} \mathrm{~L}^{-1}\right)$, com agitação manual por oito minutos. Em seguida, lavou-se com água deionizada esterilizada e transferiu-as à solução de hipoclorito de sódio $(2,5 \%)$ onde permaneceram oito minutos em agitação. Depois de lavar seis vezes com água deionizada esterilizada, foram inoculadas em tubos de ensaio com meio MS. Os tubos foram tampados, lacrados e etiquetados. O fotoperíodo de 16 horas de claro foi com lâmpada fluorescente branca fria com intensidade luminosa de 2.000 lux.

A planta obtida de cada semente gerou um clone ao ser multiplicada, por explantes de gemas apicais, quando atingiam cerca de $10 \mathrm{~cm}$ de altura. Nas primeiras repicagens a temperatura foi mantida em $25 \pm 2^{\circ} \mathrm{C}$ e nas duas últimas repicagens a temperatura foi $30 \pm 2^{\circ} \mathrm{C}$ o que fez as plantas responderem com graus variados de hiperidricidade entre e dentro dos clones. Plantas de um clone foram selecionadas e colocadas em delineamento em blocos casualizados com três repetições, cada uma com dois tubos de ensaio contendo plantas individuais. No clone havia plantas em três estádios morfofisiológicos: a) Hiperídricas: a maioria das raízes com geotropismo negativo (fora do meio de cultura); multibrotações de caules finos e de cor verde pálido; folhas translúcidas, de cor verde clara, bordas encarquilhadas e voltadas para cima; b) Intermediárias: aproximadamente a metade das raízes com geotropismo negativo e o restante com geotropismo positivo; caule fino, de cor verde e listras de cor arroxeada; folhas translúcidas, de cor verde, bordas encarquilhadas e voltadas para cima;

c) Normais: raízes com geotropismo positivo; caule de espessura normal, de cor verde na porção apical e de cor roxa na parte inferior; folhas opacas, de cor verde escura, bordas normais e no mesmo plano da lâmina foliar.

Dos três estádios foram coletadas folhas, sendo as apicais destinadas à análise isozimática e as demais à determinação da atividade enzimática da peroxidase. Das regiões apicais retirou-se $100 \mathrm{mg}$ de folhas de cada repetição, adicionou-se $300 \mathrm{~mL}$ de solução extratora número 1 sugerida por Alfenas (2006) e macerou-se em almofariz de porcelana resfriado. O macerado foi absorvido em tiras de papel cromatográfico Whatman $3 \mathrm{M}(1,4 \times 0,3 \mathrm{~cm})$. As tiras foram colocadas em eppendorf, identificadas e armazenadas a $20^{\circ} \mathrm{C}$ até o início das análises no Laboratório de Melhoramento de Hortaliças (DFT/UFV). Na eletroforese empregou-se o sistema horizontal e gel de amido nacional (maizena) a 12\%. A solução-tampão do gel e do eletrodo foi a descrita por Soltis et al. (1983), tendo a do gel: Tris $\left(0,015 \mathrm{~mol} \mathrm{~L}^{1}\right) 1,84 \mathrm{~g}$, Ácido cítrico $(0,004 \mathrm{~mol} \mathrm{~L}$ 1) 0,69 g, Água destilada $1000 \mathrm{~mL}$ e pH 7,8; e a do eletrodo: Ácido bórico $\left(0,3 \mathrm{~mol} \mathrm{~L}^{1}\right)$ 18,55 g, $\mathrm{NaOH}\left(0,1 \mathrm{~mol} \mathrm{~L}^{1}\right) 4,00 \mathrm{~g}$, Água destilada $1.000 \mathrm{~mL}$ e pH 8,6. As tiras foram colocadas nos géis e a corrida realizada a $4^{\circ} \mathrm{C}$, por 30 minutos a $150 \mathrm{~V}$ e, após retirar as tiras, a $300 \mathrm{~V}$ até o final da corrida. Após a corrida os géis foram fatiados em cinco partes (espessura $2 \mathrm{~mm}$ ), sendo as fatias intermediárias colocadas distendidas em formas do tipo pirex e imersas na solução corante específica de cada enzima. Na coloração da fosfatase ácida (ACP; EC 3.1.3.2), malato desidrogenase (MDH; EC 1.1.1.37) e peroxidase (POD; EC 1.11.1.7) foi utilizada a solução descrita por Oliveira \& Casali (1999) e na fosfogluco isomerase (PGI; EC 5.3.1.9), fosfoglucomutase (PGM; EC 5.4.2.2) e glutamato oxaloacetato transaminase (GOT; EC 2.6.1.1) foi a sugerida por Soltis et al. (1983). Na revelação dos sistemas, os géis foram colocados em cubas e mantidos em estufa a $37^{\circ} \mathrm{C}$, no escuro, exceto o sistema POD que foi mantido a $4^{\circ} \mathrm{C}$, até a revelação das bandas (cerca de uma hora). Após a revelação, lavou-se os géis em água corrente e, em seguida, fixou-os em solução de glicerina $10 \%$ (12 horas a $\left.4^{\circ} \mathrm{C}\right)$. Após adquirirem consistência, os géis foram secos pelo "método do 
bastidor", descrito em Alfenas (2006). As bandas foram identificadas por suas mobilidades relativas $(\mathrm{Mr})$ e coloração. Mr zero refere-se ao local onde foram inseridos os papéis com extratos e Mr 1,0 é o tamanho do gel. O conjunto de bandas diferentes, em suas posições, foi denominado de padrão.

A análise da atividade da peroxidase em folhas foi feita do extrato de proteínas obtidas com o uso do tampão de extração: tampão fosfato $(\mathrm{pH} 6,5) 100 \mathrm{~m} \mathrm{~mol} \mathrm{~L}^{1}, \mathrm{NaCl}$ $150 \mathrm{~m} \mathrm{~mol} \mathrm{~L}^{1}$ e Bissulfito de Sódio 0,1\%. Cerca de $300 \mathrm{mg}$ de folhas foi colocada no almofariz (resfriado e mantido a $5^{\circ} \mathrm{C}$ ), adicionado $0,9 \mathrm{~mL}$ de tampão de extração e após trituração obteve-se o extrato. Esse extrato foi mantido sobre gelo, acondicionado em eppendorf de $2 \mathrm{~mL}$ e centrifugado a $15000 \mathrm{rpm}$ por 20 minutos a $5^{\circ} \mathrm{C}$. Em seguida, retirou-se o sobrenadante e, sobre gelo, procedeu-se às leituras em espectrofotômetro (Shimadzu, modelo UV-1601) da atividade da peroxidase e da quantidade de proteínas a, respectivamente, 470 e $595 \mathrm{~nm}$. A atividade da peroxidase foi efetuada utilizando o tampão de reação: tampão fosfato (pH 6,5) $100 \mathrm{~m} \mathrm{~mol} \mathrm{~L}^{1}$, peróxido de hidrogênio e guaiacol, na proporção 3:3:2. Foi colocado $3 \mathrm{~mL}$ desse tampão em uma cubeta, adicionado $100 \mathrm{~mL}$ do extrato, agitado e, rapidamente, colocado a cubeta em leitura durante 120 segundos, com registro de 10 em 10 segundos. A quantidade de proteínas foi obtida em curva de calibração de BSA (Soro Albumina Bovina), utilizando o método de Bradford: Bradford 1,0 mL, água destilada $50 \mathrm{~mL}$ e $50 \mathrm{~mL}$ de extrato. Nas análises, substituía-se o BSA pelo extrato e, do mesmo modo, após o preparo o frasco era agitado e realizava-se a leitura entre 5 e 10 minutos. Os dados obtidos foram submetidos à análise de variância e as médias comparadas pelo teste de Tukey ( $5 \%$ de probabilidade) no aplicativo SAEG (versão 4.0).

\section{RESULTADOS E DISCUSSÃO}

$\mathrm{Na}$ análise isozimática do tecido foliar de Bidens pilosa foi revelado sete bandas no sistema peroxidase (POD), oito no fosfatase ácida (ACP), quatro no fosfogluco isomerase (PGI), duas no fosfoglucomutase (PGM), três no glutamato oxaloacetato transaminase (GOT) e 5 no malato desidrogenase (MDH) (Figura 1). Dos sistemas isozimáticos testados, dois foram polimórficos, POD e ACP, e quatro monomórficos, PGI, PGM, GOT e MDH.


Figura 1 - Conjunto de bandas e respectivas mobilidades relativas $(\mathrm{Mr})$ reveladas pelos sistemas isozimáticos: peroxidase (POD), fosfatase ácida (ACP), fosfogluco isomerase (PGI), fosfoglucomutase (PGM), glutamato oxaloacetato transaminase (GOT) e malato desidrogenase (MDH). Bandeamento obtido por eletroforese em gel de amido do tecido foliar de plântulas de mesmo clone de Bidens pilosa, nos estádios morfofisiológicos hiperídrico (1), intermediário (2) e normal (3), em cultura de tecidos. UFV, Viçosa, MG, 2000. 
A maior área e intensidade de coloração de bandas foram representadas, a coloração escura significa maior atividade. A migração das bandas ocorreu no sentido do pólo positivo, exceto POD que migrou também ao pólo negativo. A maior parte das bandas isozimáticas são comuns a todas as plântulas (17 das 29 bandas).

A ausência de variação nos sistemas PGI, PGM, GOT e MDH pode ser devido às plantas serem homogêneas geneticamente (clone) e essas isozimas desempenharem funções vitais ao vegetal: PGI e PGM são atuantes nas reações de glicólise (LEHNINGER et al., 2002); GOT está relacionada ao metabolismo dos aminoácidos, em diversos compartimentos celulares (TAIZ \& ZEIGER, 2004); MDH age no movimento de malato no citoplasma e pelas membranas de organelas, como a mitocôndria (SPINOLA et al., 2000). PGI, PGM e GOT também foram monomórficas em plantas de cinco populações naturais de B. pilosa analisadas por Grombone-Guaratini et al. (2005).

A variação no número de bandas de POD e ACP nos três padrões indica a expressão diferencial de genes que codificam essas enzimas em fases fisiológicas específicas (ALFENAS, 2006), como na hiperidricidade. Houve menor número de bandas no sistema POD nas plantas normais (uma banda) e no sistema ACP nas hiperídricas (três bandas). No sistema POD, Oliveira \& Casali (1999) também encontraram uma banda em plantas de B. pilosa mantidas in vivo. ACP e POD são sistemas polimórficos que se mostram úteis no estudo de modificações fisiológicas (ALFENAS, 2006), como marcadores da senescência de sementes de milho estudadas por Spinola et al. (2000). No sistema ACP houve decréscimo no número de bandas com a hiperidricidade. ACP ocorre em diversos compartimentos celulares e atua na hidrólise de éster fosfato, agindo sobre fosfolipídios de membrana e provocando a peroxidação destes lipídios. Atua também no metabolismo do ATP, gerando energia utilizada pela célula em diversos processos e no transporte ativo celular (LEHNINGER et al., 2002; TAIZ \& ZEIGER,
2004). O polimorfismo da peroxidase pode ser devido à sua atividade enzimática em vários compartimentos da célula vegetal seja no protoplasto, como o glioxissomo e o vacúolo, ou fora dele, aderida à parede celular ou no espaço intercelular. Em cada local exerce funções diversas na conversão de compostos orgânicos ou inorgânicos, características importantes na adaptação do organismo ao ambiente (TAIZ \& ZEIGER, 2004), o que poderia ocorrer no cultivo in vitro, em menor ou maior intensidade, daí a necessidade e uso do polimorfismo.

A análise da atividade enzimática da peroxidase foi maior nas plantas hiperídricas e intermediárias em relação às normais (Tabela 1 ).

A atividade das plantas hiperídricas e intermediárias foi, em média, mais de 55\% superior à das plantas normais, o que mostra ser a peroxidase efetiva na resposta ao estresse ambiental. Saher et al. (2004) observaram intenso aumento de atividade de peroxidase em plantas hiperídricas de Dianthus caryophyllus L. e admitiram ser evidência direta da geração de $\mathrm{H}_{2} \mathrm{O}_{2}$ em tecidos hiperídricos de folhas, pois esse acúmulo de formas tóxicas de oxigênio induziria às anormalidades observadas na morfologia. De acordo com Kevers et al. (2004), as substâncias tóxicas são geralmente eliminadas por interações cooperativas de defesas enzimáticas e antioxidantes, sendo a atuação de sistemas protetores contra formas de oxigênio ativos o que explicaria o aumento da atividade da peroxidase. A hipótese de estresse oxidativo tem como base a investigação da hiperidricidade em outras plantas (CHEN \& ZIV, 2001). As plantas hiperídricas e intermediárias tiveram maior resposta enzimática de peroxidase, correspondendo aos padrões isozimáticos com uma banda de coloração mais escura.

Em Bidens pilosa as anormalidades observadas nas folhas, caules e raízes possibilitaram separar os três tipos morfofisiológicos. As diferenciações morfológicas detectadas na hiperidricidade são, segundo Chen \& Ziv (2001), relativas à baixa lignificação e redução drástica da

Tabela 1 - Média dos tratamentos de atividade enzimática da peroxidase obtida de tecidos foliares de Bidens pilosa. UFV, Viçosa, Minas Gerais, 2000.

\begin{tabular}{lcc}
\hline Tratamentos & Média ${ }^{(*)}$ & Comparações \\
\hline Hiperídrica & 9,272 & $\mathrm{~A}$ \\
Intermediária & 9,184 & $\mathrm{~A}$ \\
Normal & 5,891 & $\mathrm{~B}$
\end{tabular}

(*) Média das três repetições; as médias seguidas de pelo menos uma mesma letra não diferem significativamente pelo teste de Tukey ( $5 \%$ de probabilidade). 
camada cuticular provocando a aparência translúcida. A atividade aumentada da peroxidase pode estar associada à melhoria no catabolismo da auxina (KEVERS et al., 2004). A auxina, produzida nos ápices caulinares, é transportada pelas células parenquimáticas do cilindro vascular até a base do explante onde regula a formação das raízes adventícias e seu ângulo de orientação, ou seja, seu geotropismo (TAIZ \& ZEIGER, 2004). Se houve alteração da peroxidase nas folhas é possível detectar diferença na raiz, seja na forma ou no comportamento geotrópico, como foi observado nas plantas hiperídricas e intermediárias.

A peroxidase portanto tem potencial marcador da hiperidricidade, com variação no número de bandas isozimáticas e na sua atividade. Entender o processo pode auxiliar na solução do problema da hiperidricidade em cultura de tecidos.

\section{CONCLUSÕES}

A análise isozimática de peroxidase e fosfatase ácida mostrou-se efetiva na separação de plantas hiperídricas, intermediárias e normais.

A resposta enzimática de peroxidase foi maior em plantas hiperídricas e intermediárias comparadas com as normais, tendo correspondência ao padrão de bandas isozimáticas de coloração mais escuras.

\section{REFERÊNCIAS BIBLIOGRÁFICAS}

ALFENAS, A. C. (Ed.). Eletroforese e marcadores bioquímicos em plantas e microrganismos. 2. ed. Viçosa: UFV, 2006. 627 p.

CHEN, J.; ZIV, M. The effect of ancymidol on hyperhydricity, regeneration, starch and antioxidant enzymatic activities in liquid-culture Narcissus. Plant Cell Reports, New York, v. 20, p. 22-27, 2001.

CHEN, S.; SCHOPFER, P. Hydroxyl-radical production in physiological reactions. European Journal of Biochemistry, [S.1.], v. 260, n. 3, p. 726-735, 1999.

CUZZUOL, G. R. F.; GALLO, L. A.; ALMEIDA, M.; CROCOMO, O. J. Control of carnation vitrification (Dianthus caryophyllus L.) in vitro. Scientia Agricola, Piracicaba, v. 52, n. 3, p. 604-614, 1995.
GRATTAPAGLIA, D.; MACHADO, M. A. Micropropagação. In: TORRES, A. L.; CALDAS, L. S.; BUSO, J. S. (Eds.). Cultura de tecidos e transformação genética de plantas. Brasília, DF: Embrapa-SPI/CNPH, 1998. v. 1, p. 183-260.

GROMBONE-GUARATINI, M. T.; SEMIR, J.; SOLFERINI, V. N. Low allozymic variation in the Bidens pilosa $\mathrm{L}$. Complex (Asteraceae). Biochemical Genetics, New York, v. 43, n. 7/8, p. 335-345, 2005.

KEVERS, C.; FRANCK, T.; STRASSER, R. J.; DOMMES, J.; GASPAR, T. Hyperhydricity of micropropagated shoots: a typically stress-induced change of physiological state. Plant Cell, Tissue and Organ Culture, Dordrechet, v. 77, p. 181-191, 2004.

LEHNINGER, A. L.; NELSON, D. L.; COX, M. M.Princípios de bioquímica. 3. ed. São Paulo: Sarvier, 2002. 975 p.

OLIVEIRA, J. E. Z.; CASALI, V. W. D. Caracterização isozimática de acessos de Bidens pilosa L. Revista Brasileira de Plantas Medicinais, Botucatu, v. 2, n. 1, p. 1926, 1999.

SAHER, S.; PIQUERAS, A.; HELLIN, E.; OLMOS, E. Hyperhydricity in micropropagated carnation shoots: the role of oxidative stress. Physiology Plantarum, Copenhagen, v. 120, n. 1, p. 152-161, 2004.

SOLTIS, D. E.; HAUFLER, C. H.; DARROW, D. C.; GASTONY, G. J. Starch gel electrophoresis of ferns: a compilation of griding buffers, gel and electrode buffers, and staining schedules. American Fern Journal, Vienna, v. 73 , n. 1, p. 9-27, 1983.

SPINOLA, M. C. M.; CÍCERO, S. M.; MELO, M. Alterações bioquímicas e fisiológicas em sementes de milho causadas pelo envelhecimento acelerado. Scientia Agricola, Piracicaba, v. 57, n. 2, p. 263-270, 2000.

TAIZ, L.; ZEIGER, E. Fisiologia vegetal. Porto Alegre: Artmed, $2004.719 \mathrm{p}$.

VALDES, H. A. L.; REGO, H. P. L. Bidens pilosa Linné, Revista Cubana de Plantas Medicinales, Habana, v. 6, n. 1, p. 28-33, 2001. 